\title{
El TEMA DE la DiCTADURA EN la OBRA DE ISABEL ALLENDE
}

\author{
Monika BREZOVÁKOVÁ \\ Universidad Constantino el Filósofo de Nitra, Eslovaquia
}

\begin{abstract}
En): The paper deals with dictatorship in the selected novel by a Hispanic author. At the beginning, the paper focuses primarily on thinking about the meaning of literature and later on moves to the artistic depiction of dictatorship in Hispanic literature. In order to illustrate the reflection of dictatorship and dictator in the novel we focus on the work of Chilean writer Isabel Allende and her novel My Invented Country, in which she portrays Chile through characteristics of the people.
\end{abstract}

Keywords (En): dictatorship; dictator; Isabel Allende; Chile; exile

Palabras claves (Es): dictadura; dictador; Isabel Allende; Chile; exilio

\section{La dictadura en la literatura}

El escritor peruano Mario Vargas Llosa (1936) dijo: «Las palabras son actos. A través de una escritura uno participa en la vida» (ZAMBRANO, 2001: 1). Entonces, ¿cuál es el sentido de la literatura? Y ¿qué significado tiene hablar del tema de la dictadura en las obras literarias? ¿Cuál es el «por qué» del reflejar los acontecimientos históricos, políticos y sociales a través de una óptica estéticoliteraria? Las respuestas las podemos encontrar volviendo la mirada hacia la historia de la literatura como tal, hacia unos contextos más amplios (sociales, culturales, artísticos, nacionales y transnacionales, etc.), hacia los valores que la literatura, a través de los siglos, nos transmite y conserva, hacia una memoria - colectiva e individual - cuya impronta lleva. A muchas respuestas llegamos directamente a través de la lectura de las obras, donde los escritores reflejan sus vivencias con el sistema de la dictadura o/y su actitud hacia éste y suelen expresarlas de forma ficticia o autobiográfica. Dichas obras pueden cambiar nuestra percepción sobre la vida. Estos libros no intentan ser unas crónicas políticas o históricas, sino una serie de recuerdos, que siempre son selectivos y subjetivos y están teñidos por la propia experiencia de los escritores. Durante la lectura podemos convertirnos en participantes del acontecimiento histórico y observar la vida de los personajes así como también la atmósfera de la narración ubicada en un pasado más o menos lejano en el tiempo. Como lectores, ahondamos en la historia, sentimos la tensión y el miedo con los personajes, vivimos sus tragedias. Al mismo tiempo, sentimos curiosidad por saber cómo terminará la historia. Después de la lectura formamos opiniones personales. Esto nos pasa cuando leemos una obra que cuenta la historia de una dictadura.

Ya sabemos que el tema de la dictadura ha tenido amplia resonancia en la narrativa del mundo hispánico. Hispanoamérica ha constituido más de una vez el 
escenario de novelas que tratan de este tema. La literatura cumple un papel instructivo y llega a ser un modelo, un medio para la justicia, o sea, nos enseña cuáles son los valores y virtudes. La literatura constituye un observatorio para el estudio de la cultura, de la historia de una comunidad y, al mismo tiempo, es una lente para leer el pasado de un país (GARAY, 2013: 20-21).

Aunque sobre el tema de la dictadura se han publicado numerosos libros literarios, el tema sigue siendo actual y es importante continuar con su interpretación también hoy en día. Como escribió Octavio Paz: «La obra sobrevive gracias a las interpretaciones de sus lectores» (PAZ, 1993: 18), que a través de los siglos cambian, las sustituyen nuevas generaciones, «cada una dueña de una interpretación distinta» (18).

\section{EI reflejo de la dictadura en la obra de Isabel Allende}

En el contexto del tema me gustaría interpretar una de las obras de Isabel Allende, la famosa autora chilena. Me doy cuenta del riesgo que corro al volver mi atención hacia esta escritora, dado que, en cuanto a su escritura, existe una imponente recepción literaria a nivel mundial. En este momento prefiero dejarme guiar por las palabras de Paz, así que les propongo la mirada de mi generación (generación de los años noventa). Es la misma Allende la que me arroja el guante cuando dice: «Las generaciones más jóvenes creen que el mundo comenzó con ellos. Lo sucedido antes no les interesa» (ALLENDE, 2017: 193). Esta opinión la formula en su libro de ensayos Mi país inventado (2003). Y esto es una razón para hacerlo, para demostrar que nosotros no podemos olvidar los acontecimientos históricos y que cada generación, incluso la nuestra, puede contribuir con su punto de vista.

Isabel Allende es una de los muchos autores que en la literatura chilena tratan el tema de la dictadura militar de Augusto Pinochet (1973 - 1989). Entre ellos destacan por ejemplo: Antonio Skármeta (1940), Roberto Bolaño (1953 - 2003), Carlos Cerda (1942 - 2001), Hernán Valdés (1934), Ariel Dorfman (1942). En los últimos meses me he dedicado al estudio de las obras de la dictadura escritas por tres chilenos: Isabel Allende, Antonio Skármeta y Roberto Bolaño. En sus libros podemos encontrar rasgos similares - la imagen del terror de la dictadura y sus consecuencias para la gente inocente, la lucha por la libertad y la crítica de un régimen político represivo. En la interpretación, me interesa la manera artística (estético-literaria) de los autores de reflejar la dictadura, su lucha por los derechos humanos o el compromiso con el humanismo.

Isabel Allende, chilena nacida en Lima (Perú), tiene una experiencia con la dictadura militar de 1973. Cuando en Chile tuvo lugar el golpe militar encabezado por Augusto Pinochet, Allende, como sobrina del presidente Salvador Allende, se exilió a Venezuela. En su obras La casa de los espíritus (1982), De amor y de sombra (1984), Eva Luna (1987), Paula (1994), Mi país inventado (2003) y La Suma de los Días (2007) describe los acontecimientos políticos y sociales del régimen pinochetista. Es interesante cómo el fluir del tiempo se plasma en su nuevo libro y le ofrece una nueva perspectiva de cómo mirar atrás. Igualmente, condena la dictadura, pero, al mismo tiempo, confiesa que determinó su trayectoria en la vida: «Uno de los eventos más definitivos fue el golpe militar de 1973. Si no fuera por 
este acontecimiento, seguramente yo nunca hubiera emigrado de Chile, no sería escritora y no estaría casada con un americano viviendo en California, tampoco me acompañaría esta larga nostalgia y hoy no estaría escribiendo estas páginas» (ALLENDE, 2017: 165).

El exilio forma parte de la dictadura, es una consecuencia del régimen. Además, provoca sentimientos profundos de pérdida: «De la noche a mañana me convertí en extranjera en mi propia tierra, hasta que finalmente debí partir, porque no podía vivir y criar a mis hijos en un país donde imperaba el temor y donde no había lugar para disidentes como yo» (ALLENDE, 2017: 17). No tiene sentido hacer diferencias entre quienes salieron de forma compulsiva y quienes lo hicieron de manera voluntaria, porque unos y otros son igualmente exiliados, ya que sus motivaciones políticas son las mismas (CÁRDENAS, 2003). Isabel Allende se siente culpable de haber abandonado su país y se pregunta qué habría sucedido si se hubiera quedado. Llega a la conclusión de que nadie realmente puede responder esa pregunta. Pero lo que sabe y de lo que está segura es de que no sería escritora sin haber pasado por la experiencia del exilio.

Precisamentepor este motivo, la escritura de Isabel Allende se ha constituido fuera de Chile, pero toda la experiencia con el destierro fortaleció su pertenencia a este país. Chile hoy en día sigue siendo su espacio geográfico-cultural, donde sitúa la mayoría de sus novelas. Lo que capta la atención es, además, la relación de la autora con ese país suyo - real, pero a la vez inventado e imaginario. Isabel Allende crea una imagen de país a través de varios rasgos y características típicas de la gente de Chile. En su libro de ensayos se pregunta ¿quiénes son los chilenos? Le resulta difícil definirlos por escrito. Les caracteriza por la religiosidad, por la sobriedad y la conservación de las tradiciones. A lo largo de la obra les define a través de varios recursos retóricos - sobre todo, con metáforas y epítetos. Les atribuye numerosos complementos. Cuando crea una imagen de su pueblo, la explica y establece contrastes. Por ejemplo, dice: «Se ha dicho mucho que somos envidiosos, que nos molesta el triunfo ajeno. Es cierto, pero la explicación no es envidia, sino sentido común: el éxito es anormal» (ALLENDE, 2017: 117). Otro ejemplo es: «Somos gente con sentido del humor y nos gusta reírnos, aunque en el fondo preferimos la seriedad» (ALLENDE, 2017: 125). Describe el carácter de su pueblo, sus costumbres, defectos y virtudes y no olvida mencionar a mujeres fuertes y hombres machistas. Todo el retrato lo hace de una manera amable y se percibe su cariño hacia al pueblo. Todas las características de los chilenos la llevan a crear una imagen de país inventado, que se encuentra dentro de su cabeza y da vida a numerosos personajes e historias, así que en sus obras capta Chile en toda su complejidad.

Uno de los objetivos de mis consideraciones es también cómo Allende refleja el tema de la dictadura en sus obras y cuáles son las diferencias entre la manera de expresarlo en las obras ficticias y en las autobiográficas. Sus obras ficticias contienen muchos elementos autobiográficos y presentan los acontecimientos de la historia chilena de un modo implícito. Por ejemplo, en las obras como La casa de los espíritus o De amor y de sombra no se mencionan las fechas ni los años concretos de la dictadura. Además, es interesante analizar el personaje del dictador, porque no se menciona su nombre ni el del presidente de la patria. Se conocen por los nombres como «Presidente»o «General»: «El presidente apareció en televisión 
pidiendo paciencia» (ALLENDE, 2018: 348). El dictador es un personaje misterioso, no se sabe nada de su interior o de su personalidad. Sólo se conoce por sus actos exteriores.

Por el contrario, en los ensayos autobiográficos como Mi país inventado, que también son una creación artística, o sea la construcción y una interpretación de la realidad por parte del autor, aunque el propósito de presentar la dictadura de Allende no cambia, la escritora intenta presentar los hechos y eventos de un modo explícito, es decir, no oculta nada, expresa lo que pasó, cómo lo vio y cómo se sintió. Sin ocultar la realidad, Allende expresa la atmósfera del terror y el miedo. De un modo explícito, también presenta el personaje del dictador, que ya aparece como una persona real, con nombre propio: «¿Quién era realmente Pinochet, ese soldado que tanto marcó a Chile con su revolución capitalista y dos décadas de represión? [...] Admirado por unos, odiado por otros, temido por todos, fue posiblemente el personaje de nuestra historia que más poder ha tenido en sus manos y por más largo tiempo» (ALLENDE, 2017: 192).

Allende ya no describe solamente la crueldad de los tiempos de la dictadura. A través de una de las características de los chilenos - la del humor - retrata el atributo de los presidentes, porque, como dice: «La popularidad de un personaje se mide por los chistes que provoca» (ALLENDE, 2017: 125). De este modo habla del presidente Jorge Alessandri (1958 - 1964) y Salvador Allende (1908 - 1973). Según sus ensayos: «Dicen que el presidente Salvador Allende inventaba chistes sobre él mismo - algunos bastante subidos de color - y los echaba a rodar» (ALLENDE, 2017: 125-126).

A través de las características del pueblo chileno Allende irónicamente describe también al dictador: «El general Pinochet no quiso pasar a la historia como usurpador del poder, sino como legítimo presidente, para lo cual tuvo que cambiar la Constitución. Por una de esas ironías tan abundantes en la historia, después se vio atrapado en las leyes que él mismo había creado para perpetuarse en el cargo» (ALLENDE, 2017: 113).

Lo que considero valioso es también que en el libro de ensayos Mi país inventado Isabel Allende presta atención no solo a todos los que condenaron la dictadura, sino que también menciona a los que estaban de acuerdo con el régimen. El paso del tiempo le permite reflexionar sobre las razones por las que la gente apoyó la dictadura. ¿Ha sido por ingenuidad? ¿O la esperanza de esa gente por un futuro mejor? Allende muestra que aquellas personas creyeron que los militares iban a limpiar el país: «Se terminó la delincuencia, no hay muros pintarrajeados con grafitti, todo está limpio y gracias al toque de queda los maridos llegan temprano a la casa» (ALLENDE, 2017: 190). Al fin, la escritora llega a la conclusión de que la gente estaba de acuerdo con la dictadura solamente hasta que tuvieron la experiencia directa con ella, hasta que sintieron la pérdida.

En las obras de Isabel Allende y las de los otros escritores chilenos podemos encontrar numerosos ejemplos de brutalidad, de terror y de violencia como consecuencias del poder de la dictadura. Éstos son los recuerdos, las memorias que trasmiten los escritores. Son testimonios de los acontecimientos crueles de una época que no podemos olvidar. Al contrario, debemos mencionarlos para que la historia no se repita. Además, en las obras podemos encontrar algo más. La 
esperanza - de un mejor futuro, de la libertad, de tiempos sin guerras ni regímenes políticos represivos. Y ésta se puede encontrar también en la obra de Allende. Por ejemplo, al final de la obra De amor y de Sombra, cuando los personajes Irene y Francisco tienen que exiliarse y abandonar su país: «En la luz dorada del amanecer se detuvieron para ver su tierra por última vez. - ¿Volveremos? - murmuró Irene. Volveremos - replicó Francisco. Y en los años que siguieron, esa palabra señalaría sus destinos: volveremos, volveremos...» (ALLENDE, 1984: 144). Así, la literatura es como un mensaje lanzado en una botella al mar con la esperanza de que arribe a la otra orilla. No se sabe quién será su lector, pero lo importante es qué transmite y qué podemos tomar de ella.

\section{BIBLIOGRAFÍA}

ALLENDE Isabel (1984), De amor y de sombra, in: http://www.anffos.cl/Descargas/BIBLIOTECA/Isabel\%20Allende\%20$\% 20 \mathrm{De} \% 20$ Amor $\% 20 \mathrm{y} \% 20 \mathrm{de} \% 20$ Sombra.pdf

ALLENDE Isabel (2018), Dom duchov, Bratislava, Slovart.

Allende Isabel (2017), Mi país inventado, Barcelona, Penguin Random House Grupo Editorial.

CÁRDENAS María Teresa (2003), Literatura chilena del exilio. Rastros de una obra dispersa, in: http://chile.exilio.free.fr/chap03f.htm.

GARAY C Sol Marina (2013), Literatura chilena de exilio, un vacío epistemológico, Estudios Filológicos, p. 17-26.

PAZ Octavio (1993), Sor Juana Inés de la Cruz o Las trampas de la fe, Barcelona, Editorial Seix Barral.

ZAMBRANO Gregory (2001), Mario Vargas Llosa y la política de la violencia en América Latina (A propósito de dictadores y novelas), in: FORGUES Roland (ed.), Mario Vargas Llosa, escritor, ensayista, ciudadano y político, Lima, Editorial Minerva, p. 277-301. 